\title{
ARMAZENAMENTO DE SEMENTES DE GIRASSOL EM TEMPERATURAS SUBZERO: ASPECTOS FISIOLÓGICOS E BIOQUÍMICOS ${ }^{1}$
}

\author{
SOLANGE CARVALHO BARRIOS ROVERI JOSÉ2; ANTONIETA NASSIF SALOMÃO; TÂNIA \\ DA SILVEIRA AGOSTINI COSTA4; JANAÍNA TENÓRIO TRANCOSO TAVARES DA SILVA; \\ CÁSSIO COSTA DA SILVA CURI ${ }^{6}$
}

\begin{abstract}
RESUMO - O grande avanço obtido na produção agropecuária se deve, dentre outros fatores, a capacidade brasileira de incorporar e utilizar recursos genéticos. A Embrapa Recursos Genéticos e Biotecnologia é a empresa responsável pela conservação em longo prazo de germoplasma semente, conservados a $-20^{\circ} \mathrm{C}$. Para garantir a qualidade do material conservado, minimizando o processo de deterioração, é necessário que se mantenham as condições adequadas de armazenamento, realizando o manejo correto do germoplasma. Os objetivos dessa pesquisa foram avaliar o efeito do teor de água nas sementes sobre a tolerância das mesmas ao armazenamento em temperaturas subzero de $-20{ }^{\circ} \mathrm{C}$ e $-196{ }^{\circ} \mathrm{C}$, bem como associar essa tolerância aos aspectos fisiológicos e bioquímicos. Foi objetivo também verificar o efeito da umidificação prévia das sementes sobre a qualidade fisiológica das mesmas, após armazenamento. A qualidade das sementes foi avaliada pelos testes de condutividade elétrica, primeira contagem e contagem final do teste de germinação, e determinação do índice de peróxidos. Sementes de girassol podem ser secadas até 3,2\% de teor de água em sílica gel ou em câmara de secagem e armazenadas a $-20{ }^{\circ} \mathrm{C}$ ou $-196{ }^{\circ} \mathrm{C}$, sem perda de germinação e vigor. Menor deterioração das sementes, avaliada pelo índice de peróxidos, é observada em sementes armazenadas em nitrogênio líquido. O tratamento de umidificação deve ser utilizado na avaliação de plântulas na primeira contagem do teste de germinação e no teste de condutividade elétrica.
\end{abstract}

Termos para indexação: germinação, vigor, conservação, nitrogênio líquido, câmara fria.

\section{STORAGE OF SUNFLOWER SEEDS IN SUB-ZERO TEMPERATURES: PHYSIOLOGICAL AND BIOCHEMICAL ASPECTS}

\begin{abstract}
The significant progress in Brazilian agricultural production has been due its capacity to incorporate and use genetic resources. Embrapa Genetic Resources and Biotechnology is the institution responsible for the long-term conservation of the seed germplasm of many crops, stored at $-20{ }^{\circ} \mathrm{C}$. Appropriate storage is necessary for correct germplasm management, to ensure the quality of the material stored and minimize the deterioration process. The objectives
\end{abstract}

\footnotetext{
${ }^{1}$ Submetido em 18/08/2009. Aceito para publicação em 27/01/2010.

${ }^{2}$ Eng.. Agr., DSc., Embrapa Recursos Genéticos e Biotecnologia, Caixa Postal 02.372, CEP: 70770-917 - Brasília, DF solangebr@cenargen. embrapa.br

${ }^{3}$ Eng. Florestal., MSc., Embrapa Recursos Genéticos e Biotecnologia, antoniet@cenargen.embrapa.br
}

\footnotetext{
${ }^{4}$ Farmacêutica, DSc, Embrapa Recursos Genéticos e Biotecnologia, tânia@cenargen.embrapa.br

${ }^{5}$ Bióloga, Graduanda, Centro Universitário de Brasília - UniCEUB jtenorio@cenargen.embrapa.br

${ }^{6}$ Zootecnista, MSc., Embrapa Recursos Genéticos e Biotecnologia, cassiocuri@cenargen.embrara.br.
} 
of this study were to evaluate the effect of seed water content on the tolerance to storage at subzero temperatures of $-20^{\circ} \mathrm{C}$ and $-196{ }^{\circ} \mathrm{C}$, to associate the tolerance level with physiological and biochemical aspects and to verify the effect of the pre-humidification of seeds on physiological quality after storage. Seed quality was evaluated by tests of electrical conductivity, first and final count of germination and determination of the peroxide index. Sunflower seeds can be dried to $3.2 \%$ of water content in silica gel or in a drying chamber and stored at $-20{ }^{\circ} \mathrm{C}$ or $-196{ }^{\circ} \mathrm{C}$ without loss of germination and vigor. Seed deterioration, evaluated by the peroxide index, was lower in seeds stored in NL. The humidification treatment was important for the evaluation of seedlings in the first count of germination test and the electrical conductivity test.

Index terms: germination, vigor, conservation, liquid nitrogen, cold chamber.

\section{INTRODUÇÃO}

O conhecimento e a preservação dos recursos genéticos vegetais são fundamentais à garantia da sustentabilidade e da segurança alimentar da população brasileira. Para que a diversidade dos recursos genéticos vegetais possa estar disponível, é importante, quando exequível, a conservação de sementes em bancos de germoplasma, de modo a resguardá-las de alterações em sua qualidade genética, fisiológica, sanitária e física.

O armazenamento de sementes para fins de preservação de recursos genéticos tem por objetivo manter a integridade e a viabilidade daquelas estruturas vegetais por períodos prolongados. A conservação de sementes da Coleção Base da Embrapa consiste em seu armazenamento com baixos teores de água, em torno de $5 \pm 2 \%$, à temperatura de $-20{ }^{\circ} \mathrm{C}$ (Faiad et al., 2001; Rao et al., 2007). Para tanto, a secagem é realizada em câmara com controles de temperatura $\left(20-22{ }^{\circ} \mathrm{C}\right)$ e umidade relativa do ar (15-17\%). Outra alternativa para a redução do grau de umidade é o emprego de sílica gel, vantajosa pela possibilidade do alcance de porcentagens muito baixas de água. (Gómez-Campo, 2006).

Embora a temperatura de $-20{ }^{\circ} \mathrm{C}$ proporcione a manutenção da viabilidade de sementes com diferentes teores de água (Hong et al., 2005), existe, para cada temperatura de armazenamento, um teor de água crítico para extensão do período de longevidade das mesmas (Ellis e Hong, 2006). O tempo decorrido para redução de $50 \%$ da porcentagem de germinação inicial de sementes de girassol com 4-8\% de água, armazenadas a $-18{ }^{\circ} \mathrm{C}$ foi de 50 anos (Walters et al., 2005). O armazenamento de sementes dos gêneros Stylosanthes (Costa et al., 2008) e Hordeum (Pinto et al., 2008) a $-20{ }^{\circ} \mathrm{C}$ possibilitou manutenção da qualidade fisiológica das mesmas por $25 \mathrm{e}$ 17 anos, respectivamente.

Outra técnica para conservação de sementes em longo prazo tem sido a criopreservação, com resultados promissores para espécies florestais (Medeiros et al., 1992; Salomão, 1995; Reis e Cunha, 1997; Salomão, 2002; Gonzaga et al., 2003) e oleaginosas (Stanwood, 1987; Gonzáles-Benito e Perez-Garcia, 2001). A taxa de congelamento em nitrogênio líquido é um fator importante a ser considerado, principalmente em sementes de oleaginosas que são mais sensíveis ao congelamento rápido (Vertucci, 1989a).

Em geral, baixos teores de água de sementes e temperaturas do ar do ambiente de armazenamento proporcionam prolongamento do período de viabilidade das mesmas. No entanto, a insuficiência de dados sobre conservação em longo prazo dificulta o entendimento do processo de deterioração sob tais condições. As pesquisas sobre deterioração de sementes são realizadas, normalmente, em condições de temperatura do ar e teores de água das sementes mais elevada, contrária às predominantes na conservação em longo prazo.

Os sintomas fisiológicos mais evidentes decorrentes da deterioração das sementes são aparentes durante a germinação e o desenvolvimento inicial das plântulas. Outra manifestação da deterioração durante o armazenamento tem sido a desestruturação do sistema de membranas, como consequência do ataque aos seus constituintes químicos pelos radicais livres. A instabilidade química dos lipídios constitui um dos fatores preponderantes para a queda do desempenho das sementes de várias espécies, especialmente das oleaginosas. Peroxidação lipídica e 
estresse oxidativo têm causado deterioração das sementes de oleaginosas durante seu envelhecimento. Em sementes de girassol, reduções de vigor e de viabilidade durante o envelhecimento acelerado estão associadas com a diminuição do potencial de enzimas antioxidantes e, desse modo, elevação da peroxidação lipídica (Torres et al., 1997).

Assim, torna-se de utilidade a realização de testes que avaliem o desenvolvimento da plântula, a integridade estrutural das membranas, bem como a ocorrência de peroxidação lipídica, em sementes armazenadas em temperaturas subzero, com diferentes teores de água. Outra preocupação quando do trabalho em Bancos de Germoplasma é o dano por embebição durante a germinação, uma vez que o grau de umidade das sementes é reduzido. Esses danos podem ser minimizados pelo condicionamento, antes da realização do teste de germinação (Hong e Ellis, 1996), que propicia elevação gradual do teor de água das sementes antes do contato com a água líquida do substrato; caso contrário, injúrias às células poderiam ser provocadas.

Os objetivos dessa pesquisa foram avaliar o efeito do teor de água de sementes de girassol em sua tolerância ao armazenamento em temperaturas subzero de $-20{ }^{\circ} \mathrm{C}$ e $-196{ }^{\circ} \mathrm{C}$, bem como associar essa tolerância aos aspectos fisiológicos e bioquímicos. Foi objetivo também verificar o efeito da umidificação prévia das sementes sobre a qualidade fisiológica das mesmas, após armazenamento.

\section{MATERIAL E MÉTODOS}

Foram utilizadas sementes de girassol (Helianthus annuus L.) provenientes da Empresa de Sementes "Helianthus do Brasil", sediada em Uberlândia - MG, com teor de água de 4,7\% (Brasil, 1992), germinação de 95\% (Brasil, 1992) e teor de óleo de 48,8\% (Pomeranz e Meloan,1994). As sementes tiveram seu teor de água elevado para $10,2 \%$, que constituiu o valor inicial (Ui) do experimento. Para tanto, foram pré-embebidas em germinador tipo "Mangelsdorf, regulado para a temperatura de $25^{\circ} \mathrm{C}$, dentro de sacos de papel tipo "kraft", até $10,2 \%$ de teor de água. Em seguida, as sementes foram submetidas à secagem artificial, em câmara refrigeradora de secagem, à temperatura de $22 \pm 2{ }^{\circ} \mathrm{C}$ e $18 \%$ de umidade relativa do ar, até teores de água de 7,4; 3,2 e 2,9\%, e em sílica gel disposta em caixa plástica $(11,5 \times 11,5 \times 3,5$ $\mathrm{cm})$ contendo tela de aço, sobre a qual as sementes foram esparramadas em camada única e o recipiente vedado com parafilme, até teores de água de 5,3; 3,2 e 2,1\%. Essas sementes submetidas à secagem e as sementes com umidade de $10,2 \%$ (Ui) e 4,7\% (controle) foram acondicionadas em sacos aluminizados, hermeticamente fechados, e, assim, imersas diretamente em nitrogênio líquido (NL, $-196^{\circ} \mathrm{C}$ ), com taxa de congelamento de 230 ${ }^{\circ} \mathrm{C} \cdot \mathrm{min}^{-1}$, ou armazenadas em câmara fria a $-20^{\circ} \mathrm{C}$.

Após três meses, as sementes foram mantidas por $24 \mathrm{~h} \mathrm{em}$ isopor, para aquelas armazenadas em câmara a $-20{ }^{\circ} \mathrm{C}$, e em temperatura ambiente por $5 \mathrm{~h}$, para as sementes imersas em NL. Parte das sementes de ambos os ambientes de armazenamento foi então acondicionada em envelopes aluminizados e armazenada em freezer a -18 ${ }^{\circ} \mathrm{C}$, para posterior análise de peroxidação de lipídeos, e o restante submetido às avaliações fisiológicas, com ou sem tratamento de umidificação: a) umidificação - as sementes foram esparramadas em camada única sobre uma tela de aço inox colocada dentro de caixa plástica transparente $(11,5 \times 11,5 \times 3,5 \mathrm{~cm})$, contendo em seu interior $40 \mathrm{~mL}$ de água destilada, assegurada a ausência de contato com a água; as caixas foram mantidas por $22 \mathrm{~h}$ em condições de laboratório, após o que foram realizados testes de germinação e de vigor, bem como a determinação do grau de umidade das sementes; b) sem umidificação - com a realização dos mesmos testes fisiológicos e determinação do teor de água das sementes imediatamente após o armazenamento.

O grau de umidade foi determinado com duas subamostras de $2 \mathrm{~g}$ de sementes para cada tratamento, utilizando-se cápsulas de alumínio com diâmetro de 4,5 $\mathrm{cm}$. As amostras permaneceram em estufa regulada a $105 \pm 3{ }^{\circ} \mathrm{C}$, durante $24 \mathrm{~h}$ (Brasil, 1992) e a porcentagem do teor de água foi calculada na base do peso fresco, correspondente à média de ambas as subamostras.

Para o teste de germinação, quatro repetições de 25 sementes foram semeadas entre papel toalha tipo Germitest umedecido com água destilada na proporção de 2,5 mL.g ${ }^{-1}$ de papel seco. As sementes foram mantidas em germinador regulado na temperatura de $25{ }^{\circ} \mathrm{C}$ por cinco dias, quando se procedeu às avaliações das plântulas normais (Brasil, 1992). Aos três dias após instalação do teste de germinação foi realizada a primeira contagem, computando-se as plântulas normais. Conjuntamente com o teste de germinação, foi também computado o número de plântulas normais com raiz primária $\geq 7 \mathrm{~cm}$ de comprimento quando da primeira e última contagem do teste, com expressão dos resultados em porcentagem. 
$\mathrm{Na}$ avaliação da condutividade elétrica, quatro repetições de 25 sementes, aparentemente intactas, foram pesadas $(0,001 \mathrm{~g})$ para cada tratamento e, em seguida, imersas em $75 \mathrm{~mL}$ de água destilada por $24 \mathrm{~h}$, à temperatura de $25{ }^{\circ} \mathrm{C}$. Por meio de um condutivímetro de massa da marca Digimed DM 31, previamente calibrado, foi efetuada a leitura da condutividade da solução de embebição das sementes de cada material e os resultados expressos em $\mu \mathrm{S} / \mathrm{cm} / \mathrm{g}$ de sementes (Vieira e Krzyzanowski, 1999).

Para determinação do índice de peróxidos, as sementes foram trituradas em liquidificador $\mathrm{e}$ posteriormente em processador, obtendo uma moagem fina. Para a extração do óleo, foi utilizado o equipamento TE 044 e éter de petróleo como solvente. A extração foi conduzida a $70{ }^{\circ} \mathrm{C}$ por um período de $1 \mathrm{~h}$. Após extração, a amostra foi filtrada, primeiramente em papel absorvente, e, em seguida, em papel contendo $22 \mathrm{~g}$ de sulfato de sódio. A evaporação do solvente foi realizada num evaporador modelo TE 210, utilizando-se a temperatura inicial de $37^{\circ} \mathrm{C}$, por $15 \mathrm{~min}$, elevada para $50{ }^{\circ} \mathrm{C}$, por $10 \mathrm{~min}$, após o que o óleo foi armazenado em geladeira, no escuro, até a realização das análises. $\mathrm{O}$ índice de peróxidos foi determinado conforme metodologia proposta pela AOCS Cd 8-53 (AOCS, 1993), com modificações. Cinco gramas de óleo $( \pm 0,5$ g) foram pesadas em triplicata e a cada uma delas foram adicionados $12 \mathrm{~mL}$ de clorofórmio, $18 \mathrm{~mL}$ de ácido acético e $1 \mathrm{~mL}$ de solução saturada de iodeto de potássio. Após agitação vigorosa e a permanência da amostra em repouso por $5 \mathrm{~min}$ no escuro, foram acrescentados 75 $\mathrm{mL}$ de água ultra pura e procedeu-se à titulação com solução de tiossulfato de sódio $0,01 \mathrm{~N}$, na presença do indicador amido a $1 \%$. O cálculo foi realizado de acordo com a fórmula abaixo com expressão dos dados em $\mathrm{mEq}$ peróxidos $/ \mathrm{Kg}$ de amostra.

Índice de peróxido $=(\mathrm{S}-\mathrm{B}) \times \mathrm{N} \times 1000 /$ peso da amostra, em que:

$\mathrm{S}=$ titulação da amostra em $\mathrm{mL}$ de tiossulfato

$\mathrm{B}=$ titulação do branco em $\mathrm{mL}$ de tiossulfato

$\mathrm{N}=$ normalidade do tiossulfato

Para cada método de secagem, o delineamento experimental foi o inteiramente casualizado, com quatro repetições, em esquema fatorial $5 \times 2 \times 2$ sendo cinco graus de umidade das sementes $(10,2 ; 4,7 ; 5,3 ; 3,2 \mathrm{e}$ $2,1 \%$ secadas em sílica gel e 10,2 4,7; 7,4; 3,2 e 2,9\% secadas em câmara de secagem), dois ambientes de armazenamento $\left(-20\right.$ e $\left.-196{ }^{\circ} \mathrm{C}\right)$ e dois tratamentos de umidificação (com e sem). Para a análise de índice de peróxido, o delineamento foi o inteiramente casualizado, com três repetições. Os dados foram interpretados estatisticamente por meio da análise de variância e as médias comparadas pelo teste de Scott Knott em nível de $5 \%$. As análises foram realizadas no programa estatístico Sisvar (Sistema de Análise de Variância) (Ferreira, 2000).

\section{RESULTADOS E DISCUSSÃO}

O tratamento de umidificação nas sementes armazenadas foi eficiente em elevar o teor de água das mesmas para valores acima de $14 \%$, próximos aos valores mencionados por Hong e Ellis (1996), que foi de 14 a $17 \%$ (Tabela 1$)$.

TABELA 1. Teores médios de água obtidos de sementes submetidas à umidificação após armazenamento em temperaturas de $-20^{\circ} \mathrm{C} \mathrm{e}-196{ }^{\circ} \mathrm{C}$.

\begin{tabular}{lcc}
\hline \multirow{2}{*}{ Teor de água antes do armazenamento } & \multicolumn{2}{c}{ Teor de água após armazenamento $(\%)$} \\
\cline { 2 - 3 } & $-196{ }^{\circ} \mathrm{C}$ & $-20{ }^{\circ} \mathrm{C}$ \\
\hline $4,7 \%$ (controle) & 16,5 & 16,2 \\
$10,2 \%$ (umidade inicial) & 15,6 & 15,8 \\
$5,3 \%$ (secagem em sílica) & 14,6 & 15,1 \\
$3,2 \%$ (secagem em sílica) & 14,0 & 15,0 \\
$2,1 \%$ (secagem em sílica) & 16,2 & 16,0 \\
$7,4 \%$ (câmara secagem) & 16,1 & 16,0 \\
$3,2 \%$ (câmara secagem) & 14,1 & 14,9 \\
$2,9 \%$ (câmara secagem) & 17,2 & 16,8 \\
\hline
\end{tabular}


Para a primeira contagem do teste de germinação (Tabela 2) das sementes secadas em câmara de secagem foi verificada interação entre grau de umidade $\mathrm{x}$ ambiente de armazenamento e grau de umidade $\mathrm{x}$ tratamento de umidificação. Na temperatura de armazenamento de $-20^{\circ} \mathrm{C}$ foi observado melhor desempenho das sementes controle, ou seja com $4,7 \%$ de teor de água, e no armazenamento em NL $\left(-196{ }^{\circ} \mathrm{C}\right)$, a maior porcentagem de plântulas normais na primeira contagem do teste de germinação ocorreu nas sementes com teores de água mais baixos, ou seja, com 3,2 e 2,9\%, superando o desempenho das sementes controle. Para cada temperatura de armazenamento existe um teor de água crítico para que as sementes apresentem maior longevidade e, nesta pesquisa, essa umidade crítica foi mais baixa quando o congelamento foi rápido, a $-196{ }^{\circ} \mathrm{C}$. Vertucci (1989a) observou redução do vigor de sementes de girassol congeladas a $-190{ }^{\circ} \mathrm{C}$ com teores de água de $1,96 \%$ e $2,9 \%$. Mas a taxa de congelamento para essas sementes com 1,96 e $2,9 \%$ foi maior ou igual a $200{ }^{\circ} \mathrm{C} \cdot \mathrm{min}^{-1}$; para teores de água entre 13,7 e $16,6 \%$ a taxa de congelamento recomendada foi de 40 a 200 ${ }^{\circ} \mathrm{C} . \mathrm{min}^{-1}$ e para sementes de soja esse teor de água variou de 22,4 a $28 \%$. Nessa pesquisa, o menor teor de água das sementes foi de $2,9 \%$ e a taxa de congelamento em NL foi de $230{ }^{\circ} \mathrm{C} \cdot \mathrm{min}^{-1}$. Quando as sementes foram umidificadas (Tabela 2) após armazenamento, não houve diferenças significativas para a porcentagem de plântulas normais entre as sementes com diferentes teores de água. Entretanto, diferenças no vigor ocorreram para as sementes que foram avaliadas sem tratamento prévio de umidificação. Menor porcentagem de plântulas normais foi verificado para sementes com teor de água mais elevado, de $7,4 \%$ e $10,2 \%$, e não houve diferenças entre o desempenho das sementes com teor de água de 3,2\%, $2,9 \%$ e sementes controle. Esse baixo desempenho das sementes com umidade de $7,4 \%$ e $10,2 \%$ pode ter sido ocasionado pelo maior estresse térmico ocasionado nas sementes armazenadas com teores mais elevados de água; no entanto, a umidificação prévia propiciou aumento da germinação dessas sementes.

TABELA 2. Valores médios de plântulas normais (\%) na primeira contagem do teste de germinação de sementes submetidas (C/ Ud) ou não (S/ Ud) ao tratamento de umidificação após secagem em câmara até diferentes teores de água e armazenadas em temperatura sub-zero $\left(-20{ }^{\circ} \mathrm{C} \mathrm{e}-196{ }^{\circ} \mathrm{C}\right)$.

\begin{tabular}{|c|c|c|c|c|c|c|c|c|c|c|c|c|c|c|}
\hline & \multicolumn{2}{|r|}{$4,7 \%$} & \multicolumn{3}{|c|}{$10,2 \%$} & \multicolumn{3}{|c|}{$7,4 \%$} & \multicolumn{3}{|c|}{$3,2 \%$} & \multicolumn{3}{|c|}{$2,9 \%$} \\
\hline$-20^{\circ} \mathrm{C}$ & 89 & a A & 81 & $\mathrm{~b}$ & $\mathrm{~A}$ & 82 & $\mathrm{~b}$ & A & 83 & $\mathrm{~b}$ & A & 81 & $\mathrm{~b}$ & B \\
\hline$-196^{\circ} \mathrm{C}$ & 83 & b $B$ & 80 & $\mathrm{~b}$ & A & 81 & & A & 86 & $\mathrm{a}$ & A & 88 & $\mathrm{a}$ & A \\
\hline & \multicolumn{2}{|r|}{$4,7 \%$} & \multicolumn{3}{|c|}{$10,2 \%$} & \multicolumn{3}{|c|}{$7,4 \%$} & \multicolumn{3}{|c|}{$3,2 \%$} & \multicolumn{3}{|c|}{$2,9 \%$} \\
\hline $\mathrm{C} / \mathrm{Ud}$ & 87 & a A & 84 & $\mathrm{a}$ & A & 84 & $\mathrm{a}$ & A & 86 & $\mathrm{a}$ & A & 81 & $\mathrm{a}$ & B \\
\hline $\mathrm{S} / \mathrm{Ud}$ & 85 & a A & 77 & b & B & 79 & & B & 83 & $\mathrm{a}$ & A & 88 & $\mathrm{a}$ & A \\
\hline
\end{tabular}

Médias seguidas pela mesma letra minúscula na linha, e maiúscula na coluna, não diferem estatisticamente, a $5 \%$ de probabilidade.

$\mathrm{Na}$ avaliação do desenvolvimento de raiz na primeira contagem do teste de germinação houve diferenças significativas para o ambiente de armazenamento e para a interação grau de umidade e tratamento de umidificação. Comparando o desempenho das sementes nos dois ambientes de armazenamento, o desenvolvimento de raiz foi maior para as sementes armazenadas em NL, com média geral de $35 \%$, comparados com o ambiente de câmara a -20 ${ }^{\circ} \mathrm{C}$, em que a média foi de $27 \%$ de plântulas com raiz maior ou igual a $7 \mathrm{~cm}$. Quando as sementes foram submetidas ao tratamento de umidificação após armazenamento (Tabela 3), o desempenho das sementes com umidade de $10,2,3,2$ e $2,9 \%$ foi superior ao das sementes controle. É importante mencionar que sementes com $10,2 \%$ de umidade não foram submetidas ao processo de secagem, o que pode ter influenciado no resultado. No tratamento sem umidificação, apenas as sementes com umidade de 2,9\% apresentaram maior vigor. $\mathrm{O}$ tratamento de umidificação para as sementes com diferentes umidades não prejudicou o seu desempenho nesse teste, e proporcionou uma maior porcentagem de plântulas normais para as sementes com umidade de $10,2,3,2 \%$ e $2,9 \%$.

No entanto, na contagem final do teste de germinação das sementes, não houve diferenças entre os fatores estudados, nem interação entre eles, e a média geral foi de $87 \%$. O mesmo resultado foi obtido quando se avaliou o desenvolvimento de plântulas, por meio do comprimento de raiz, e a porcentagem média de sementes germinadas 
com raiz primária maior que $7 \mathrm{~cm}$ foi de $77 \%$. Sendo assim, sementes de girassol podem ser armazenadas em NL, como em câmara a $-20{ }^{\circ} \mathrm{C}$, com os diferentes teores de água estudados nessa pesquisa e o tratamento de umidificação pode ou não ser utilizado, que não haverá redução na germinação das sementes. Mas é importante mencionar que testes de vigor são imprescindíveis para o acompanhamento da deterioração de sementes, principalmente em condições de armazenamento em longo prazo, em que sementes são submetidas ao estresse hídrico e térmico. Temperatura de armazenamento de $-20^{\circ} \mathrm{C}$ também permitiu a sobrevivência de sementes de cenoura, amendoim, alface, colza e cebola por dez anos numa ampla faixa de umidade (2,0 a 6,8\%), o que não ocorreu quando a temperatura foi de $20{ }^{\circ} \mathrm{C}$ (Hong et al., 2005). A viabilidade das sementes de soja e ervilha, com teores de água entre 4,7 e $15,2 \%$, não foi afetada por temperatura de congelamento de $-18,-30,-50,-80$ e $-180^{\circ} \mathrm{C}$. Para níveis de hidratação inferiores a $4,7 \%$, a sobrevivência de sementes de soja foi limitada por temperaturas subzero. A taxa de congelamento das sementes congeladas a $-180{ }^{\circ} \mathrm{C}$ foi de $45{ }^{\circ} \mathrm{C} \cdot \mathrm{min}^{-1} \mathrm{e}$, nas demais temperaturas de congelamento, de 12 a $15{ }^{\circ} \mathrm{C} \cdot \mathrm{min}^{-1}$ (Vertucci, 1989b). Esses valores de taxa de congelamento foram inferiores aos valores utilizados nesse trabalho, que foi de $230{ }^{\circ} \mathrm{C} \cdot \mathrm{min}^{-1}$, o que pode ter favorecido o desempenho das sementes de girassol com umidade abaixo de $4,7 \%$.

TABELA 3. Valores médios de plântulas normais (\%), com raiz primária maior que $7 \mathrm{~cm}$, na primeira contagem do teste de germinação de sementes submetidas $(\mathrm{C} / \mathrm{Ud})$ ou não $(\mathrm{S} /$ Ud) ao tratamento de umidificação após secagem em câmara até diferentes teores de água e armazenadas em temperatura sub-zero $\left(-20^{\circ} \mathrm{C}\right.$ e $\left.-196{ }^{\circ} \mathrm{C}\right)$.

\begin{tabular}{lrcrrr}
\hline & $4,7 \%$ & $10,2 \%$ & $7,4 \%$ & $3,2 \%$ & $2,9 \%$ \\
\hline $\mathrm{C} / \mathrm{Ud}$ & $30 \mathrm{bA}$ & $36 \mathrm{aA}$ & $28 \mathrm{bA}$ & $40 \mathrm{aA}$ & $42 \mathrm{aA}$ \\
$\mathrm{S} / \mathrm{Ud}$ & $28 \mathrm{bA}$ & $22 \mathrm{bB}$ & $22 \mathrm{bA}$ & $18 \mathrm{bB}$ & $47 \mathrm{aA}$ \\
\hline
\end{tabular}

Médias seguidas pela mesma letra minúscula na linha, e maiúscula na coluna, não diferem estatisticamente, a $5 \%$ de probabilidade.

No teste de condutividade elétrica (CE), houve interação tripla entre os fatores, e os resultados podem ser observados na Tabela 4, para o desdobramento do tratamento de umidificação dentro de cada nível de umidade das sementes e ambiente de armazenamento. Nesse teste é avaliada a quantidade de lixiviados exudados das sementes, e quanto maior o valor obtido, menor o vigor das sementes. O tratamento de umidificação foi benéfico para as sementes armazenadas em temperaturas sub-zeros com diferentes teores de água, com exceção das sementes armazenadas a $-20{ }^{\circ} \mathrm{C}$, com $2,9 \%$ de umidade, em que os valores observados nas sementes não umidificadas foram menores, de $56,21 \mu \mathrm{S} / \mathrm{cm} / \mathrm{g}$ de sementes. É importante mencionar que, para as sementes secadas até $2,9 \%$ de umidade, o período de permanência das sementes na câmara foi maior. Para as sementes submetidas ao tratamento de umidificação, os valores de $\mathrm{CE}$ foram os mesmos para as sementes armazenadas tanto a $-20{ }^{\circ} \mathrm{C}$ quanto a $-196{ }^{\circ} \mathrm{C}$, para cada umidade da semente estudada, exceção para as sementes controle, em que foram observados menores valores de CE $(68,76$ $\mu \mathrm{S} / \mathrm{cm} / \mathrm{g}$ de sementes), para as sementes armazenadas a $-196{ }^{\circ} \mathrm{C}$. Quando o tratamento de umidificação não foi realizado, houve diferenças nos valores de $\mathrm{CE}$ para as sementes armazenadas em NL e a $-20{ }^{\circ} \mathrm{C}$ para as sementes com umidades mais baixas, de 3,2 e 2,9\%, além das sementes controle. Verificou-se também que o congelamento mais rápido em NL aumentou a quantidade de exsudatos liberados das células dessas sementes, sugerindo que os danos ocorridos nas membranas celulares pelo congelamento rápido foram revertidos pela umidificação antes da instalação do teste.

Para as sementes que foram secadas em sílica gel, houve diferenças para o ambiente de armazenamento e tratamento de umidificação das sementes na porcentagem de plântulas normais obtida na primeira contagem do teste de germinação. Maior porcentagem de plântulas normais foi verificada em sementes armazenadas a -20 ${ }^{\circ} \mathrm{C}$, com valor médio de $84 \%$, comparado com $81 \%$ no ambiente de armazenamento de $-196{ }^{\circ} \mathrm{C}$. O tratamento de umidificação proporcionou um aumento de 3\% na germinação das sementes, ou seja, de $81 \%$ para sementes não tratadas para $84 \%$ de germinação para as sementes umidificadas previamente ao teste. A avaliação das sementes aos três dias da semeadura pode não ter propiciado o tempo necessário para que os mecanismos de reparo das células tenham sido realizados, e as sementes secadas em sílica, com uma taxa de secagem mais rápida, podem ter se beneficiado pela umidificação prévia, que promoveu uma maior germinação das sementes. 
TABELA 4. Valores médios de condutividade elétrica $(\mu \mathrm{S} / \mathrm{cm} / \mathrm{g})$ de sementes submetidas $(\mathrm{C} /$ Ud) ou não (S/ Ud) ao tratamento de umidificação após secagem em câmara até diferentes teores de água e armazenadas em temperatura sub-zero $\left(-20^{\circ} \mathrm{C} \mathrm{e}-196^{\circ} \mathrm{C}\right)$.

\begin{tabular}{lcccc}
\hline $\begin{array}{c}\text { Umidade/Ambiente } \\
\text { armazenamento }\end{array}$ & \multicolumn{2}{c}{$\mathrm{C} / \mathrm{Ud}$} & \multicolumn{2}{c}{$\mathrm{S} / \mathrm{Ud}$} \\
\hline $10,2 \% /-20{ }^{\circ} \mathrm{C}$ & 65,84 & $\mathrm{bA}$ & 70,74 & $\mathrm{aA}$ \\
$10,2 \% /-196{ }^{\circ} \mathrm{C}$ & 66,84 & $\mathrm{bA}$ & 72,73 & $\mathrm{aA}$ \\
$4,7 \% /-20{ }^{\circ} \mathrm{C}$ & 72,90 & $\mathrm{aA}$ & 73,38 & $\mathrm{aB}$ \\
$4,7 \% /-196{ }^{\circ} \mathrm{C}$ & 68,76 & $\mathrm{bB}$ & 82,15 & $\mathrm{aA}$ \\
$7,4 \% /-20{ }^{\circ} \mathrm{C}$ & 69,73 & $\mathrm{aA}$ & 72,20 & $\mathrm{aA}$ \\
$7,4 \% /-196{ }^{\circ} \mathrm{C}$ & 65,87 & $\mathrm{bA}$ & 74,57 & $\mathrm{aA}$ \\
$3,2 \% /-20{ }^{\circ} \mathrm{C}$ & 67,83 & $\mathrm{bA}$ & 72,04 & $\mathrm{aB}$ \\
$3,2 \% /-196{ }^{\circ} \mathrm{C}$ & 67,62 & $\mathrm{bA}$ & 84,28 & $\mathrm{aA}$ \\
$2,9 \% /-20{ }^{\circ} \mathrm{C}$ & 70,12 & $\mathrm{aA}$ & 56,21 & $\mathrm{bB}$ \\
$2,9 \% /-196{ }^{\circ} \mathrm{C}$ & 69,08 & $\mathrm{bA}$ & 77,61 & $\mathrm{aA}$ \\
\hline
\end{tabular}

Médias seguidas pela mesma letra minúscula na linha, e maiúscula na coluna, comparando apenas os tratamentos com a mesma umidade, não diferem estatisticamente, a $5 \%$ de probabilidade.

Para o desenvolvimento de raiz, avaliado na primeira contagem do teste de germinação de sementes (Tabela 5) houve interação entre o ambiente de armazenamento e tratamento de umidificação. Diferenças entre o armazenamento das sementes a $-20{ }^{\circ} \mathrm{C}$ e $-196{ }^{\circ} \mathrm{C}$ foram observadas somente para aquelas que não foram submetidas ao tratamento de umidificação. Esse tratamento de umidificação proporcionou melhor desempenho das sementes, promovendo um aumento de $11 \%$ na germinação das sementes armazenadas a $-20^{\circ} \mathrm{C}$.

TABELA 5. Valores médios de plântulas normais (\%), com raiz primária maior que $7 \mathrm{~cm}$, na primeira contagem do teste de germinação de sementes submetidas ( $\mathrm{C} / \mathrm{Ud})$ ou não (S/ Ud) ao tratamento de umidificação após secagem em sílica gel até diferentes teores de água e armazenadas em temperatura sub-zero $\left(-20{ }^{\circ} \mathrm{C} \mathrm{e}-196{ }^{\circ} \mathrm{C}\right)$.

\begin{tabular}{lllll}
\hline & $-196{ }^{\circ} \mathrm{C}$ & & $-20{ }^{\circ} \mathrm{C}$ \\
\hline $\mathrm{C} / \mathrm{Ud}$ & 31 & $\mathrm{aA}$ & 31 & $\mathrm{aA}$ \\
$\mathrm{S} / \mathrm{Ud}$ & 27 & $\mathrm{aA}$ & 20 & $\mathrm{bB}$ \\
\hline
\end{tabular}

Médias seguidas pela mesma letra minúscula na linha, e maiúscula na coluna, não diferem estatisticamente, a $5 \%$ de probabilidade.
$\mathrm{Na}$ contagem final, em que foram realizadas avaliações de plântulas normais, bem como comprimento de raiz, não foram observadas diferenças entre as umidades estudadas, temperatura de armazenamento, tratamento de umidificação e nem interação entre eles, como constatado também nos resultados obtidos das sementes secadas em câmara de secagem. A média geral para a germinação das sementes foi de $88 \%$ e para a porcentagem de sementes com raiz primária maior que $7 \mathrm{~cm}$, de 76\%. Gonzáles-Benito e Perez-Garcia (2001) também não verificaram diferenças entre a germinação de sementes de girassol criopreservadas com teores de água de 6,2 a $8,9 \%$ e sementes controle. Uma das vantagens da secagem em sílica é proporcionar um ambiente asséptico, reduzindo a porcentagem de sementes infectadas (PérezGarcia et al., 2007) e, embora não tenha sido objetivo desse trabalho, plântulas mais sadias foram obtidas de sementes secadas em sílica, comparadas com a secagem em câmara.

As interações dos fatores umidade e tratamento de umidificação, ambiente de armazenamento e umidificação foram significativas para o teste de condutividade elétrica (CE). Os valores de CE obtidos de sementes previamente umidificadas após armazenamento a $-196{ }^{\circ} \mathrm{C}$ e a -20 ${ }^{\circ} \mathrm{C}$ foram inferiores (Tabela 6), ou seja, para sementes secadas em sílica e submetidas às temperaturas sub-zero, a umidificação é favorável. Não houve diferenças entre os valores de CE para as sementes com diferentes teores de água quando estas foram submetidas ao tratamento de umidificação (Tabela 7). A umidificação prévia das sementes antes da instalação do teste provavelmente reverteu os danos às membranas celulares que podem ter ocorrido nas sementes submetidas ao processo de secagem, não diferenciando dos valores obtidos das sementes controle e com umidade inicial $(10,2 \%)$. No entanto, o desempenho das sementes com baixa umidade $(2,1 \%)$ foi inferior quando estas não foram submetidas à umidificação, elevando-se o valor de CE dessas sementes para $85,29 \mu \mathrm{S} / \mathrm{cm} / \mathrm{g}$ de sementes. Houve uma desestruturação do sistema de membranas das sementes secadas em sílica até teores de água mais baixos, provocando maior lixiviação de exsudatos das sementes. Para todas as umidades, o tratamento de umidificação proporcionou melhor desempenho das sementes, o que pode ter influenciado numa melhor estrutura do sistema de membranas e consequentemente numa menor quantidade de exudatos lixiviados das sementes. Valores elevados de condutividade também foram observados em cotilédones 
de soja com umidade menor que 10,7\% (Vertucci, 1989b) e a autora comentou que tal fato se deve primeiramente, aos danos por embebição, e não pela exposição a baixas temperaturas.

TABELA 6. Valores médios de condutividade elétrica $(\mu \mathrm{S} / \mathrm{cm} / \mathrm{g}$ de sementes) de sementes submetidas (C/ Ud) ou não (S/ Ud) ao tratamento de umidificação após secagem em sílica gel até diferentes teores de água e armazenadas em temperatura sub-zero $\left(-20{ }^{\circ} \mathrm{C}\right.$ e $\left.-196{ }^{\circ} \mathrm{C}\right)$.

\begin{tabular}{lllll}
\hline & \multicolumn{2}{c}{$\mathrm{C} / \mathrm{Ud}$} & \multicolumn{2}{c}{$\mathrm{S} / \mathrm{Ud}$} \\
\hline$-20{ }^{\circ} \mathrm{C}$ & 70,78 & $\mathrm{bA}$ & 75,37 & $\mathrm{aB}$ \\
$-196{ }^{\circ} \mathrm{C}$ & 67,95 & $\mathrm{bA}$ & 79,40 & $\mathrm{aA}$ \\
\hline
\end{tabular}

Médias seguidas pela mesma letra minúscula na linha, e maiúscula na coluna, não diferem estatisticamente, no nível de $5 \%$ de probabilidade.

TABELA 7. Valores médios de condutividade elétrica $(\mu \mathrm{S} / \mathrm{cm} / \mathrm{g}$ de sementes) de sementes submetidas (C/ Ud) ou não (S/ Ud) ao tratamento de umidificação após secagem em sílica gel até diferentes teores de água e armazenadas em temperatura sub-zero $\left(-20^{\circ} \mathrm{C}\right.$ e $\left.-196{ }^{\circ} \mathrm{C}\right)$.

\begin{tabular}{lccccc}
\hline & $4,7 \%$ & $10,2 \%$ & $5,3 \%$ & $3,2 \%$ & $2,1 \%$ \\
\hline C/ Ud & $70,83 \mathrm{aB}$ & $66,34 \mathrm{aB}$ & $70,46 \mathrm{aA}$ & $69,01 \mathrm{aB}$ & $70,19 \mathrm{aB}$ \\
S/ Ud & $77,77 \mathrm{bA}$ & $71,74 \mathrm{bA}$ & $75,22 \mathrm{bA}$ & $76,91 \mathrm{bA}$ & $85,29 \mathrm{aA}$
\end{tabular}

Médias seguidas pela mesma letra minúscula na linha, e maiúscula na coluna, não diferem estatisticamente, no nível de $5 \%$ de probabilidade.

Houve diferença estatística entre os tratamentos para a avaliação do índice de peróxidos (Tabela 8). Os valores de peróxidos obtidos de sementes armazenadas em temperatura de $20{ }^{\circ} \mathrm{C}$ foram mais elevados. Esses valores variaram de 14,16 a $24,06 \mathrm{mEq}$ peróxidos/ $\mathrm{kg}$ de amostra, e para as sementes armazenadas em NL, de 2,57 a 12,70. Exceção feita para as sementes armazenadas em NL com 10,2\% de umidade, em que o valor atingiu 17,53 , demonstrando que o congelamento das sementes com essa umidade pode causar injúrias às células, favorecendo a formação de peróxidos, mesmo quando utilizado a temperatura de congelamento de -20 ${ }^{\circ} \mathrm{C}$, em que o valor foi de $21,17 \mathrm{mEq} /$ peróxidos $/ \mathrm{Kg}$ de sementes. Para a temperatura de congelamento de -20 ${ }^{\circ} \mathrm{C}$, as sementes controle estavam entre os melhores tratamentos. No entanto, é possível verificar que as condições de armazenamento a $-20{ }^{\circ} \mathrm{C}$ para sementes com $4,7 \%$ de teor de água (controle) proporcionou um aumento do índice de peróxidos de 4,52 para 14,16 $\mathrm{mEq} /$ peróxidos $/ \mathrm{Kg}$ de sementes. Além da taxa de congelamento, a umidade foi um fator importante na formação de peróxidos nas células. Sementes com teores de água de $10,2 \%$, por exemplo, não foram submetidas ao processo de secagem, mas elevado índice de peróxido foi observado nessas sementes, principalmente quando armazenadas em câmara a $-20{ }^{\circ} \mathrm{C}$. Comparando com os resultados obtidos nesse teste com o de condutividade elétrica (CE) para as sementes não umidificadas, os valores mais elevados, e consequentemente os piores resultados, foram observados para as sementes armazenadas a $-196{ }^{\circ} \mathrm{C}$ (Tabela 6) e com umidade de $4,7,3,2$ e $2,9 \%$ (Tabela 4), o que não ocorreu com os resultados de índice de peróxidos, que foi melhor para esse ambiente a $-196^{\circ} \mathrm{C}$. No entanto, essa falta de relação entre peroxidação lipídica e quantidade de lixiviados das células foi explicada pela peroxidação de lipídeos de reserva, como forma de proteção das membranas das células de sementes de girassol (Bailly et al., 1996 e Gidrol et al., 1989, citados por Kibinza et al., 2006). O envelhecimento acelerado de sementes de girassol, com $23 \%$ de teor de água, induziu tanto a perda da viabilidade como o acúmulo de MDA ("malondialdehyde"), mas tal envelhecimento não resultou em mudanças significativas nos valores de condutividade elétrica. $\mathrm{O}$ acúmulo de $\mathrm{H}_{2} \mathrm{O}_{2}$ e peroxidação lipídica pode ser resultado da diminuição da atividade de enzimas antioxidantes, e depende do grau de umidade (Bailly et al., 1996 e Gidrol et al., 1989, citados por Kibinza et al., 2006).

Pelos resultados obtidos nessa pesquisa, foi possível detectar diferenças quanto ao nível de deterioração das sementes armazenadas a $-196{ }^{\circ} \mathrm{C}$ e a $-20{ }^{\circ} \mathrm{C}$, pelo teste de índice de peróxidos, como nos demais testes de vigor. A utilização desse teste bioquímico como os demais testes de vigor é importante na escolha do teor de água das sementes mais adequado para o armazenamento a $-196{ }^{\circ} \mathrm{C}$ e a $-20^{\circ} \mathrm{C}$, que proporcionem uma maior longevidade. 
TABELA 8. Valores médios do índice de peróxidos ( $\mathrm{mEq}$ peróxidos/Kg) de sementes de girassol secadas em câmara de secagem (CS) e em sílica gel (SG) até diferentes teores de água e armazenadas a $-196{ }^{\circ} \mathrm{C}$ e a $-20{ }^{\circ} \mathrm{C}$.

\begin{tabular}{lrl}
\hline Tratamentos & Índice de Peróxidos \\
\hline$-196{ }^{\circ} \mathrm{C}(\mathrm{SG}: 5,3 \%)$ & 2,57 & $\mathrm{~A}$ \\
$-196{ }^{\circ} \mathrm{C}(\mathrm{CS}: 2,9 \%)$ & 3,20 & $\mathrm{~B}$ \\
$-196{ }^{\circ} \mathrm{C}(\mathrm{CS}: 3,2 \%)$ & 3,30 & $\mathrm{~B}$ \\
Controle $(4,7 \%)$ & 4,52 & $\mathrm{C}$ \\
$-196{ }^{\circ} \mathrm{C}(\mathrm{SG}: 2,1 \%)$ & 6,20 & $\mathrm{D}$ \\
$-196{ }^{\circ} \mathrm{C}(\mathrm{Controle}: 4,7 \%)$ & 7,33 & $\mathrm{E}$ \\
$-196{ }^{\circ} \mathrm{C}(\mathrm{SG}: 3,2 \%)$ & 7,92 & $\mathrm{~F}$ \\
$-196{ }^{\circ} \mathrm{C}(\mathrm{CS}: 7,4 \%)$ & 12,70 & $\mathrm{G}$ \\
$-20{ }^{\circ} \mathrm{C}(\mathrm{Controle:} 4,7 \%)$ & 14,16 & $\mathrm{H}$ \\
$-20{ }^{\circ} \mathrm{C}(\mathrm{CS}: 7,4 \%)$ & 14,30 & $\mathrm{H}$ \\
$-20{ }^{\circ} \mathrm{C}(\mathrm{SG}: 3,2 \%)$ & 16,38 & $\mathrm{H}$ \\
$-20{ }^{\circ} \mathrm{C}(\mathrm{SG}: 2,1 \%)$ & 17,01 & $\mathrm{I}$ \\
$-20{ }^{\circ} \mathrm{C}(\mathrm{SG}: 5,3 \%)$ & 17,36 & $\mathrm{I}$ \\
$-196{ }^{\circ} \mathrm{C}(10,2 \%)$ & 17,53 & $\mathrm{I}$ \\
$-20{ }^{\circ} \mathrm{C}(\mathrm{CS}: 2,9 \%)$ & 18,40 & $\mathrm{~J}$ \\
$-20{ }^{\circ} \mathrm{C}(10,2 \%)$ & 21,17 & $\mathrm{~K}$ \\
$-20{ }^{\circ} \mathrm{C}(\mathrm{CS}: 3,2 \%)$ & 24,06 & $\mathrm{~L}$ \\
\hline
\end{tabular}

Médias seguidas da mesma letra não diferem entre si a $5 \%$ de probabilidade.

\section{CONCLUSÕES}

Sementes de girassol podem ser secadas até 3,2\% de teor de água em sílica gel ou em câmara de secagem e armazenadas a $-20{ }^{\circ} \mathrm{C}$ ou $-196{ }^{\circ} \mathrm{C}$, sem perda de germinação e vigor.

Menor deterioração das sementes, avaliada pelo índice de peróxidos, é observada em sementes armazenadas em nitrogênio líquido.

O tratamento de umidificação deve ser utilizado na avaliação de plântulas na primeira contagem do teste de germinação e no teste de condutividade elétrica.

\section{REFERÊNCIAS}

AMERICAN OIL CHEMISTS SOCIETY. Official methods and recommended practices. 4.ed. [S.1.]: Champaign, 1993. v.3. 54p.
BRASIL. Ministério da Agricultura e Reforma Agrária. Secretaria Nacional de Defesa Agropecuária. Departamento Nacional de Defesa Vegetal. Coordenação de Laboratório Vegetal. Regras para análise de sementes. Brasília, DF, 1992. 365p.

COSTA, L.R.S.; SILVA, J.T.T.; CURI, C.C.S.; JOSÈ, S.C.B.R.; PEÑNALOZA, A.P.S. Monitoração de acessos do gênero Stylozantes da coleção de base de germoplasmasemente da Embrapa. In: SIMPÓSIO BRASILEIRO DE RECURSOS GENÉTICOS, 2., 2008, Brasília, DF. Anais... Brasília, DF: Embrapa Recursos Genéticos e Biotecnologia: Fundação de Apoio à Pesquisa Científica e Tecnológica FUNCREDI, 2008. p.372.

ELLIS, R.H.; HONG, T.D. Temperature sensitivity of the low-moisture content limit to negative seed longevity moisture content relationships in hermetic storage. Annals of Botany, v.97, n.5, p.785-791, 2006.

FAIAD, M.G.R.; GOEDERT, C.O.; WETZEL, M.M.V.S.; SILVA, D.B.; PEREIRA NETO, L. G. Banco de germoplasma desementes da Embrapa. Brasília: Embrapa Recursos Genéticos e Biotecnologia, 2001. 31p. (Embrapa Recursos Genéticos e Biotecnologia. Documentos, 71).

FERREIRA, D.F. Análises estatísticas por meio do Sisvar para Windows versão 4.0. In: REUNIÃO ANUAL DA REGIÃO BRASILEIRA DA SOCIEDADE INTERNACIONAL DE BIOMETRIA, 45., 2000, São Carlos. Programas e resumos... São Carlos, SP: UFSCar, 2000. p.255-258.

GONZAGA, T.W.C.; MATA, M.E.R.M.C.; SILVA, H.; DUARTE, M.E.M. Crioconservação de sementes de aroeira (Astronium urundeuva engl.), e baraúna (Schinopsis brasiliensis engl.). Revista Brasileira de Produtos Agroindustriais, v.5, n.2, p.145-154, 2003.

GONZALES BENITO, M.E.; PEREZ GARCIA, F. Cryopreservation of lipid-rich seeds: effect of moisture content and cooling rate on germination. Cryoletters, v.22, n.2, p.135-140, 2001.

GÓMEZ CAMPO, C. Long term seed preservation: updated standards are urgent. Madrid: Universidad Politécnica de Madri, 2006. 4p. (Monographs ETSIA, 168).

HONG, T.D.; ELLIS, R.H. A protocol to determine seed storage behavior. Rome: IPGRI, 1996. 62p. (Technical Bulletin n.1).

HONG, T.D.; ELLIS, R.H.; ASTLEY, D.; PINNEGAR, A.E.; GROOT, S.P.C.; KRAAK, H.L. Survival and vigour of ultra-dry seeds after ten years of hermetic storage. Seed 
Science and Technology, v.33, n.2, p.449-460, 2005.

KIBINZA, S.; VINEL, D.; CÔME, D.; CORBINEAU, F. Sunflower seed deterioration as related to moisture content during ageing, energy metabolism and active oxygen species scavening. Physiologia Plantarum, v.128, n.3, p.496-506, 2006.

MEDEIROS, A.C.S.; CZARNESKI, C.M.; FREITAS, G.F. Criopreservação de sementes de aroeira (Astronium urundeuva (Fr.All.) Engl.). Revista do Instituto Florestal, v.4, n.4, p.544-547, 1992.

PÉREZ GARCIA, F.; GONZÁLEZ BENITO, M.E.; GÓMEZ CAMPO, C. High viability recorded in ultra-dry seeds of 37 species of Brassicaceae after almost 40 years of storage. Seed Science and Technology, v.35, n.1, p.143153, 2007.

PINTO, G.R.R.; SCHWINGEL， L.C.; PÁDUA， J.G.; GOEDERT, C.O. Efeito do armazenamento a longo prazo na viabilidade de acessos de cevada (Hordeum vulgare). In: SIMPÓSIO BRASILEIRO DE RECURSOS GENÉTICOS, 2., 2008, Brasília, DF. Anais... Brasília, DF: Embrapa Recursos Genéticos e Biotecnologia: Fundação de Apoio à Pesquisa Científica e Tecnológica - FUNCREDI, 2008. p.334.

POMERANZ, Y.; MELOAN, C.E. Food analysis. 3.ed. New York: Chapman \& Hall, 1994. 778p.

RAO, N.K.; DULLOO, M.E.; GHOSH, D.N.; LARINDE, M. Manual para el manejo de semillas en bancos de germoplasma. Manuales para Bancos de Germplasma No. 8. Roma, Itália: Bioversity International, 2007. 164p.

REIS, A.M.M.; CUNHA, R. Efeito do congelamento sobre a viabilidade de sementes de Anadenanthera peregrina (1.) Speg. com diferentes conteúdos de umidade. Pesquisa Agropecuária Brasileira, v.32, n.10, p.1071-1079, 1997.
SALOMÃO, A.N. Effects of liquid nitrogen storage on Ziziphus joazeiro seeds. Cryo-Letters, v.16, n.2, p.85-90, 1995.

SALOMÃO, A.N. Tropical seed species responses to liquid nitrogen exposure. Brazilian Journal of Plant Physiology, v.14, n.2, p.133-138, 2002.

STANWOOD, P.C. Survival of Sesame seeds at the temperature $\left(-196^{\circ} \mathrm{C}\right)$ of liquid nitrogen. Crop Science, v.27, n.2, p.327-331, 1987.

TORRES, M.; DE PAULA, M.; PÈREZ_OTAOLA, M.; DARDER, M.; FRUTOS, G.; MARTINEZ_ HONDUVILLA, C. Ageing-induced changes in glutathione system of sunflower seeds. Plant Physiology, v.133, n.2, p.600-604, 1997.

VERTUCCI, C.W. Effects of cooling rate seeds exposed to liquid nitrogen temperatures. Plant Physiology, v.90, n.4, p.1478-1485, 1989a.

VERTUCCI, C.W. Relationship between thermal transitions and freezing injury in pea and soybean seeds. Plant Physiology, v.90, n.3, p.1121-1128, 1989b.

VIEIRA, R.D.; KRZYZANOWSKI, F.C. Teste de condutividade elétrica. In: KRZYANOWSKI, F. C.; VIEIRA, R.D.; FRANÇA NETO, J.B. (Ed.). Vigor de sementes: conceitos e testes. Londrina: ABRATES, 1999. cap. 4, p.1-26.

WALTERS, C.; WHEELER, L.M.; GROTENHULS, J.M. Longevity of seeds stored in a genebank: species characteristics. Seed Science Research, v.15, n.1, p.1-20, 2005. 